\title{
Image Analysis of Night Scape using Lyrics
}

\author{
Hiroki Komai and Kazunari Tanaka
}

\begin{abstract}
Night scape has a beauty that attracts people. In recent years, due to the spread of cameras and SNS, there are many new trends and new popular spots. As a byproduct, this seems to attract tourist. In this research, the characteristics of the night scape were analyzed using the photos and post contents from SNS. As a result, by the analysis to evaluate a part of the values, the examples: the perseverance, the painfulness and the merriment are appeared of the night scape.
\end{abstract}

\section{Keywords - Image analysis, Night scape, SNS}

\section{INTRODUCTION}

Night scape attracts a lot of people regardless of race, gender, generation. It is a visual stimulus that brings healing to modern people who have various stresses in modern society. The night scape has an ability to allow one to collect themselves. In recent years, popularization of smartphones and digitization of cameras has progressed, giving many people easy access to cameras that are now high performance. At the same time, information exchange platforms of SNS (social network service) have become popular. It became possible to "share" one's information or "moments" with unspecified numbers of people. SNS leads trends and when people shoot a night scape with their camera and post it to SNS the post receives a lot of attention and that location becomes a popular night scenic spot. That popular night scenic spot is then sought after by tourists which leads to increased regional revitalization. It is indispensable to focus attention on people's consciousness to find a characteristic night scape.

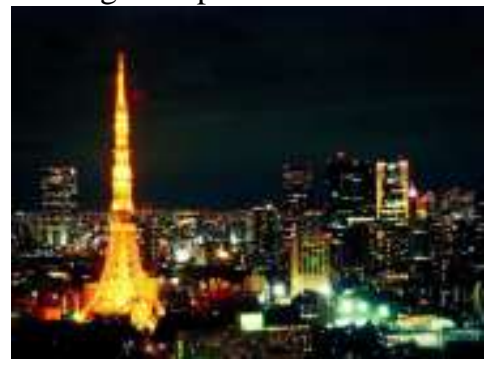

Fig. 1 Night scape

\section{PURPOSE AND METHOD}

In this research, we aim to grasp what kind of emotion people feel from a night view. This insight into emotion should become a clue for the characteristics of an optimal night view.

For the research method, we collected lyrics from songs related to nightscape photos and night scenes.

Hiroki Komai, Osaka Institute of Technology, Japan

Kazunari Tanaka, Osaka Institute of Technology, Japan
After that, analyze classification and characteristics of nightscape photograph and analyze the lyrics.

Next, we retrieve words obtained by analysis of collected lyrics and classify them.

Finally, from the relationship between the analysis result of the night scape photograph and the words obtained by the lyrics analysis, we analyze the image of the nightscape picture and make conclusions.

\section{How To COLLECT Pictures}

Flickr is a photo posting site from overseas boasting the most photos posted in the world. In Flickr, registered users can freely classify photos in Flickr with keywords called "tags". In addition, each user has a function to create a "set" in which thumbnails of a plurality of photos are arranged in the same title on their respective top page. The sets here are more flexible than the traditional file sorting method, it is possible to put one picture in multiple sets or not in any set. In this way, it is easy to classify and search pictures, as the relationship between pictures and words has an SNS-like aspect.

Furthermore, Flickr has released its own API (Application Programming Interface), allowing applications to "mash up" with SNS.

In this research, we selected Flickr as a photo collection site.

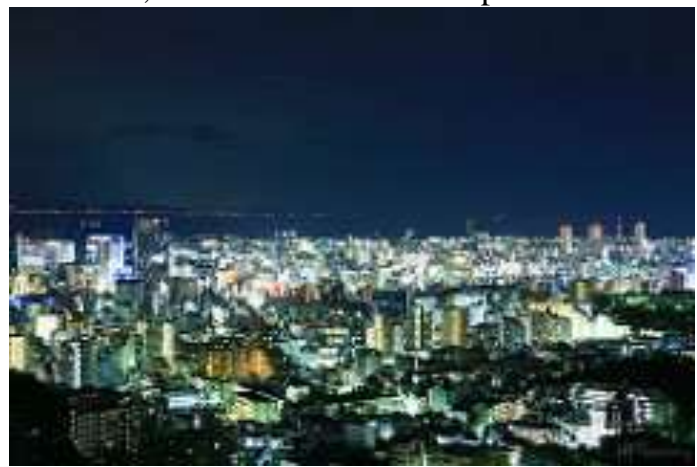

Fig. 2 Examples of pictures collected using Flicker

\section{COllecting Night ScAPE Pictures}

In this research, we analyzed images of night scenery searching photos with "night view" tags. However, there are enormous amounts of photographs taken from countless nightscape spots making it difficult to analyze all of them. Therefore, in this research, we selected nightscape spots and targeted nightscape photographs taken within them.

Night scene spots were targeted at 26 places with reference to the website. After that, we collected photographs of the target night scenic spots and sorted out pictures other than night 
scenes. Then, six target night spot spots where the ratio of the total number of searches and night view photos exceeded $30 \%$ were taken as the target of this study.

TABLE I

PERCENTAGE OF TARGET SPOT AND NIGHT VIEW PHOTO
\begin{tabular}{|l|c|}
\hline \multicolumn{1}{|c|}{ place } & percentage(\%) \\
\hline Mount Hiei driveway & 7.6 \\
\hline Mount Oiw a view place & 0.0 \\
\hline Mount Mandor o observatory & 100.0 \\
\hline Abeno harukasu & 13.8 \\
\hline Seaside cosmos & 23.1 \\
\hline Umeda sky building & 11.2 \\
\hline Orix Honmachi building & 15.2 \\
\hline Mbunt Satsuli driveway & - \\
\hline Izumiotsu parking area & 56.1 \\
\hline Jusou Pass observatory & - \\
\hline Kanku outlook hall & 7.6 \\
\hline Hannan sky town & 50.0 \\
\hline Mount Maya & 33.6 \\
\hline Rokkou gar den terrace & 6.5 \\
\hline Mount Rokkou observatory & - \\
\hline Mount Nadamaru park & 27.3 \\
\hline Maiko park & 6.5 \\
\hline Kobe port tower & 7.8 \\
\hline Venus village & 37.8 \\
\hline Port Island north park & 66.0 \\
\hline Itami sky park & 4.1 \\
\hline Yamatedai north park & 0.4 \\
\hline Awaji service area & 5.9 \\
\hline Mount Wakakusa & 2.2 \\
\hline Shigi Ikoma sky line & 25.0 \\
\hline Saisyogamine view place & - \\
\hline
\end{tabular}

\section{V.COLLECTION OF LYRICS}

In this research, we use lyrics to analyze nightscape pictures. The lyrics to be used were for songs in which words related to night were included in lyrics out of a total of 280 songs by the ranking of sales each year from 1989 to 2016.

\section{ANALYSIS OF LYRICS}

In this research, text mining was used for lyrics analysis. Text mining is a method for discovering useful information from sentences.

It uses a method of natural language processing to extract bits from sentences by dividing sentences into words and phrases and statistically analyzing the occurrence frequency of words and the relationship between words. Therefore, text mining is considered to be an effective means for realizing the objective of analyzing a large amount of text data efficiently and objectively.

It can be divided into parts that categorize sentences by natural language processing and statistical analysis of categorized data. Therefore, in order to implement it, software that executes natural language analysis to separate sentences into words and software to perform statistical analysis are required. In the case of text mining software, there is software capable of performing both of these functions, and software only capable of categorizing the former sentences.

In this research, we analyzed lyrics using "IBM SPSS Text Analytics for Surveys" which categorizes sentences.

For lyrics of extracted songs, we extracted words expressing night scenes and adjectives and adverbs that psychologically evaluate them. Examples are shown in Table 1 and Table 2.

TABLE

EXTRACTION OF NIGHT SCENERY AND PSYCHOLOGY

\begin{tabular}{|l|l|}
\hline \multicolumn{1}{|c|}{ Night seape word } & \multicolumn{1}{c|}{ Psychological words } \\
\hline city & get over(norikoeru),miracle(dis eld),Painful(tsurai), etc... \\
light & To watch ov er(mimamoru), To succeed(setsunaku), etc... \\
\hline $\begin{array}{l}\text { sky } \\
\text { night sky }\end{array}$ & happiness(siawase),break down(kowasu),To die(kareru),etc... \\
\hline
\end{tabular}

TABLE

EXTRACTION OF NIGHT SCENERY AND PSYCHOLOGY

\begin{tabular}{|l|l|}
\hline \multicolumn{1}{|c|}{ Night seape word } & \multicolumn{1}{c|}{ Psychological words } \\
\hline city & get over(norikoeru),miracle(kis ela),Painful(tsurai),etc... \\
\hline light & To watch ov er(mimamoru), To succeed(setsunaku),etc... \\
\hline sky & happiness(siawase),break down(kowasu),To die(kareru), etc... \\
night sky & Important thing(taisetsunamono),Goodbye(sayonara) \\
\hline
\end{tabular}

\section{EVALUATION OF Night SCAPE PHOTOS THROUGH LyRICS}

In this study, we have grasped the image of the night view photograph from the relationship between the constituent elements and lyrics expressing the psychology associated with the extracted night view photo. Here, the constituent elements of night scenes are taken out, and words of psychology evaluation are arranged in parallel for each.

\section{RESULTS AND DISCUSSION}

Analysis of nightscape photos and lyrics revealed that various emotions can be obtained from the night view. The results found that night scenery attracts people with its beauty, but also that a possibility that simply feeling that it is beautiful is only part of the surface layer. Table 2 and Fig. 3, and Table 3 and Fig. 4 correspond to each other. Starting with Table 2 and Fig. 3, it can be expressed that "a hardship must be overcome". With Table 3 and Fig. 4, it can be expressed as "I hope to focus on important things". From these analyzes and considerations, it turned out that people have various emotions, regardless of their consciousness, when looking at night views. There was also a tendency that positive and negative emotions coexisted with the photographs targeted this time. These provide suggestions on how to draw out the charm of the night view attracting people.

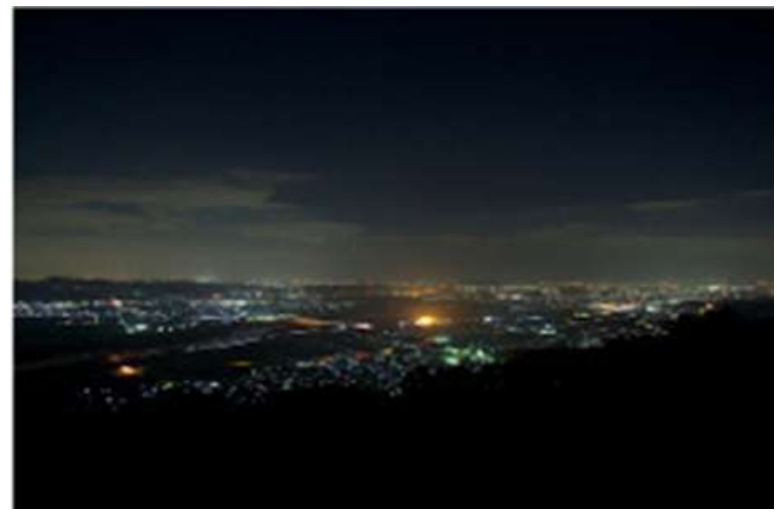

Fig. 3 Examples of pictures collected using Flicker 


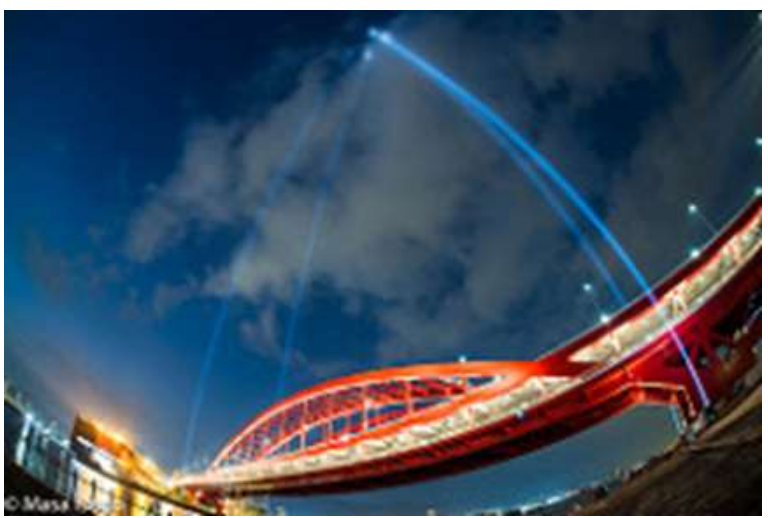

Fig. 4 Examples of pictures collected using Flicker

\section{CONCLUSION}

In this research, we tried grasping emotions and images obtained from night scenes using night view photos and lyrics. As a result, we think that we found one evaluation method of a characteristic night time landscape. Moreover, it was revealed that various emotions are obtained from the space constituent elements of night views. From this result, I think that we could grasp a part of the charm of the night view.

I think that discovering the attractiveness of night views using new indicators and methods will be significant in the future nightscape analysis. Moreover, we think that this could lead to the possibility of contributing to the creation of a characteristic night view.

\section{REFERENCES}

[1] Hiroki T, Kazunari T, Shin Y, Boundary focusing on light environment in urban space, Civil Engineering Association Kansai Branch Annual Scientific Lecture Concert Summary, IV-14, 2013.

[2] Yuji O, Kazunari T, Shin Y, Analysis and Evaluation of Landscape Based on Tourist Behavior, Geographical Information System Conference Presentation Proceedings, Vol. 26, 2017,C-1-2(CD). 